\title{
Erratum to: Novel Application of High Voltage Electrostatics Corona Ions Discharge Related to Treatment, Sanitization and Disinfection of Biological Matter Such HIV-AIDS Infected Blood
}

\author{
HAMADE Thomas A. \\ (University of Michigan - Shanghai Jiao Tong University Joint Institute, \\ Shanghai Jiao Tong University, Shanghai 200240, China) \\ (C) Shanghai Jiao Tong University and Springer-Verlag GmbH Germany, part of Springer Nature 2020
}

The original version of this article unfortunately contained outdated email address in footing, page 112. The updated email address is given below.

E-mail: hamadeta@udmercy.edu

The online version of the original article can be found at https://doi.org/10.1007/s12204-018-1916-y

E-mail: hamadeta@udmercy.edu 